\title{
СОВЕРШЕНСТВОВАНИЕ СИСТЕМЫ УПРАВЛЕНИЯ РИСКАМИ КАК ФАКТОРА УСТОЙЧИВОГО РАЗВИТИЯ НАЦИОНАЛЬНОЙ ЭКОНОМИКИ
}

\author{
(c) 2020 Иванова Дарья Геннадьевна \\ кандидат экономических наук, доцент кафедры «Мировой экономики», \\ Ростовский государственный экономический университет, Россия, Ростов-на-Дону \\ E-mail: ivanova753@yandex.ru
}

В статье раскрыты основные направления совершенствования системы управления рисками в контексте концепции устойчивого развития. Рассмотрены перспективные пути развития процесса управления рисками, а также проведен анализ инновационных инструментов, повышающих эффективность данного процесса.

Ключевые слова: система управления рисками, устойчивое развитие, технология управления, инновационные направления.

В современный период политика устойчивого развития приобрела глобальный характер - она согласована на уровне ООН и других международных организаций. Устойчивое развитие предприятия как субсистемы экономики и управление им является ключевым фактором, лежащим в основе стратегии устойчивого развития национальной экономики. В настоящее время наблюдается ряд закономерностей в нарастании темпов структурных, институциональных и рыночных изменений в экономике как на национальном, так и международном уровнях, что приводит к возникновению и росту значительного числа сложных рисков.

Под системой управления рисками подразумевается устоявшийся или постоянно меняющийся и дополняющийся комплекс мер оценки вероятности возникновения угроз [5].

На протяжении всего процесса управления осуществляются взаимосвязанные действия по обмену информацией, установлению целей, а также по идентификации, исследованию, оценке, обработке, мониторингу и анализу риска, выполняемые в соответствии с политикой, процедурами и методами менеджмента организации. В нём используется технология управления рисками, которая представляет собой совокупность приёмов, способов и инструментов, необходимых для данного процесса. Технология управления рисками базируется на реализации поэтапного регулирования (рис. 1).

Последний этап в технологии управления рисками подразумевает возвращение на любую из других стадий.

Эффективная политика управления рисками включает в себя три ключевых аспекта:

1. Разработка системы мер, направленных на предупреждение и профилактику рисков на базе мониторинга внешней и внутренней среды организации.

2. Минимизация негативных последствий, которые могут причинить риски экономической деятельности организации, что осуществляется за счет создания внешних и внутренних страховых и резервных фондов, с помощью которых можно частично или полностью компенсировать негативные последствия рисков.

3. Возможность получать в ситуации риска дополнительные доходы или иные коммерческие преимущества путем рационального использования ситуации.

За последние несколько лет выделились перспективные направления развития процесса управления рисками с точки зрения его интеграции в фирму [1]:

1. Развитие культуры управления рисками (2018 год - 85\%, 2017 год - 74\%, направление укрепило позиции).

2. Интеграция управления рисками в процесс постановки целей (2018 год - 67\%, 2017 год - 58\%, направление укрепило позиции).

3. Интеграция управления рисками в процесс бюджетирования (2018 год - 60\%, 2017 год $-48 \%$, направление укрепило позиции).

4. Внедрение инструментов количественной оценки рисков (2018 год - 55\%, 2017 год $46 \%$, направление укрепило позиции).

5. Интеграция управления рисками в процесс принятия инвестиционных решений (2018 год - 53\%, 2017 год - 48\%, направление укрепи- 


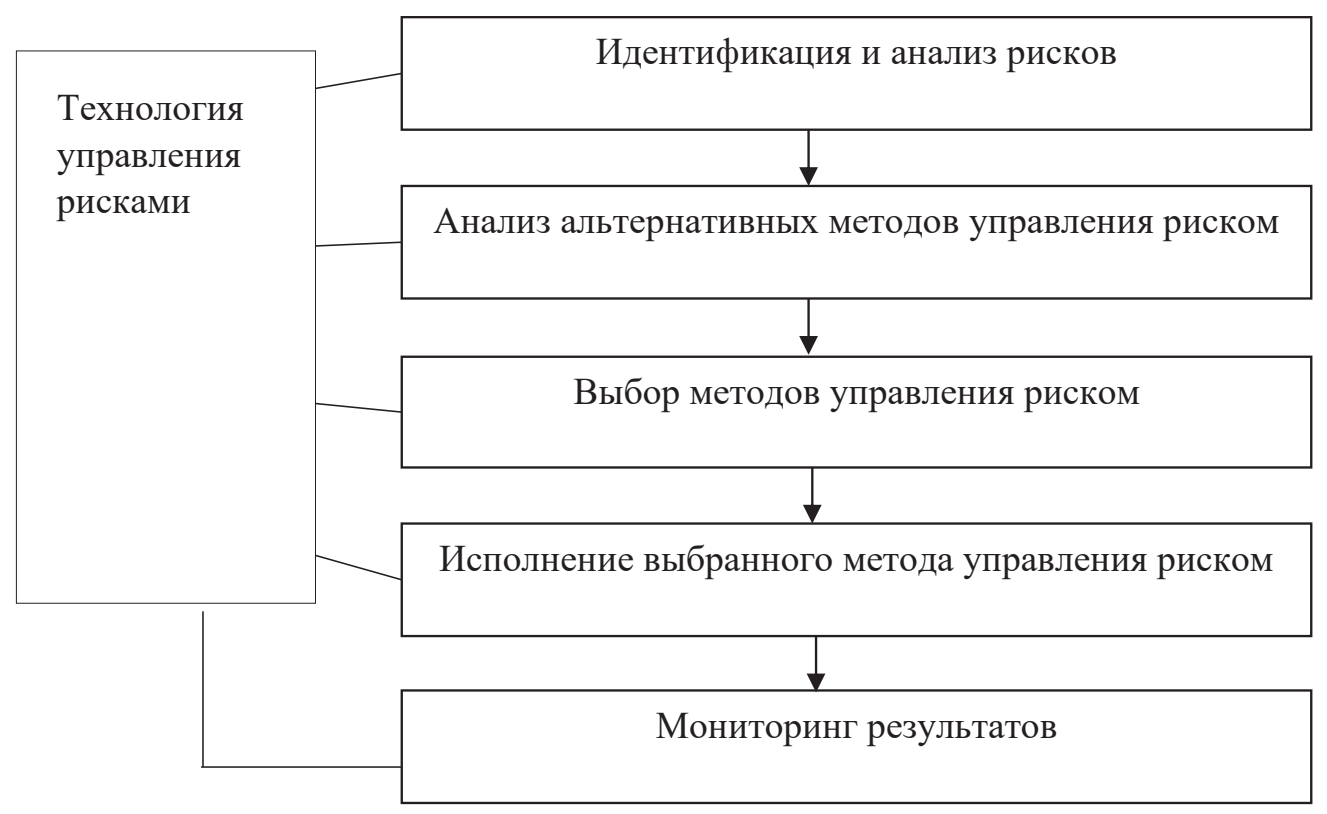

Рисунок 1. Технология управления рисками [4]

ло позиции).

6. Интеграция управления рисками в процесс стратегического планирования (51\% за 2018 год).

7. Интеграция управления рисками в производственные процессы (2018 год - 40\%, 2017 год - 50\%, направление утратило актуальность).

В целом современная система управления рисками приобретает всё новые и новые очертания. В ее структуре определяются инновационные направления, которые помогут повысить ее эффективность:

1. Использование инструментов решения противоречий (ТРИЗ - теория решения изобретательских задач) для формирования мероприятий в рамках дополнительных стратегий по управлению рисками.

Как раз данная теория и раскрывает дополнительные стратегии управления рисками.

- Использование риска.

В конкретном городе много коттеджных поселков, но покупателей мало. Имеющиеся способы донесения информации потенциальному клиенту представляются неэффективными, так как клиент с большей вероятностью не воспримет её. В таком случае, согласно ТРИЗ нужно использовать риск. Необходимо поставить себя на место потенциального потребителя. Представить ситуации, в которых он может оказаться и придумать новые способы рекламы, которые могут потребовать увеличения затрат. К приме- ру, если коттеджный посёлок находится поблизости с аэропортом, можно выстричь баркод на небольшой площади. Потенциальные клиенты могут его сфотографировать, и в их телефонах останется карта коттеджного поселка. То есть можно увеличить затраты и создать иной подход, тем самым, приняв на себя риск, но впоследствии получив больше выгоды.

- Совместное использование риска.

Любое противоречие может стать угрозой только при определенном масштабе. Иногда можно использовать риск совместно с другими организациями и получить выгоду, как от сотрудничества, так и от предотвращения негативных последствий риска.

- Усиление риска.

Если побороть риск нельзя, можно усилить его настолько, чтобы он стал неактуальным. Так, например, люди могут наносить пин-коды на банковские карты, что позволит злоумышленникам легко списать все деньги в случае, если карта попадёт к ним. В таком случае банк может выпустить особые карты, у которых на обратной стороне будет последовательность из 20 цифр. Пользователю карты нужно будет запомнить позицию первой цифры кода, тогда при инициации карты можно установить пин-код, который всегда с клиентом, но недоступен злоумышленнику, пока не отметят позицию.

Если определить риск через призму противоречий, то управление им можно осуществлять 
через разделение противоречия:

- разделение в пространстве;

- разделение во времени;

- разделение в структуре (если нельзя решить проблему, можно поменять детали).

2. Повысить качество оценки (обеспечить достоверность оценки вероятности).

Сделать это возможно двумя способами, либо определить вероятность посредством оценки влияния риска, либо объективизировать процесс оценки риска [3].

Объективизировать в данном случае значит определить признаки изменения вероятности реализации риска. В соответствии с общим подходом, чем больше таких признаков, тем выше вероятность реализации риска. Вероятность определяется как отношение числа «реализовавшихся» признаков к общему числу признаков для данного риска.

Например, компании необходимо проверить своего потенциального партнёра, иностранного контрагента, они могут учесть информационные, налоговые, учредительные, а также отражающие финансово-хозяйственную деятельность признаки.

В качестве информационного признака может быть отсутствие информации о фактическом местонахождении производственных и складских помещений или уклонение от предоставления копий документов, подтверждающих полномочия руководителя. Из налоговых признаков, например, может быть отказ от предоставления налоговой отчётности в электронном виде. А среди учредительных - регистрация на лицо, которое может управлять более чем 10 компаниями. Все эти признаки в конечном итоге могут говорить о недобросовестности контрагента. Определяется отношение этих признаков (уже «реализовавшихся») к общему числу признаков для исследуемого риска.

В любом проекте также должна быть информация о дополнительных параметрах. Стоп-факторами (наличие которых говорит о проблемах) также можно считать неточную информацию, отсутствие необходимого опыта или уклонение от авторского надзора.

3. Учесть искажения при принятии решений (исключить ловушки быстрых ответов).

Иногда при проведении экспертных оценок риска появляется вероятность неточных ответов на вопросы, когда респонденты читают вопрос, но воспринимают его исходя из собственных переживаний или настроения.

Таким образом, управление рисками является неотъемлемой частью управления организацией. Эффективная система риск-менеджмента позволит минимизировать число сложных рисков, оказывающих существенное влияние на устойчивое развитие предприятия и национальную экономику в целом.

\section{Библиографический список}

1. Оценка уровня зрелости управления рисками в России / Исследовательский центр компании «Делойт» в СНГ. // Москва, 2018.- 42 с.

2. Современные методы управления рисками в крупных проектах. Андрей Иванов. 2019. [Электронный pecypc].- Режим доступа: https://www.cfo-russia.ru/stati/index.php? SECTION_ID=70 (дата обращения: 13.10.2020)

3. Комиссарова М.А., Рыгаловский Д. М. Возможности управления рисками для достижения устойчивого развития предприятия // Российское предпринимательство. 2016. № 22. URL: https://cyberleninka.ru/article/n/ vozmozhnosti-upravleniya-riskami-dlya-dostizheniya-ustoychivogo-razvitiya-predpriyatiуa (дата обращения: 15.10.2020).

4. ГОСТ Р 51897-2002 от 30.05.2002 «Государственный стандарт Российской Федерации. Менеджмент риска. Термины и определения» // Электронный фонд правовой и нормативно - технической документации [Электронный ресурс].- Режим доступа: http://docs.cntd.ru/document/1200030150 (дата обращения: $05.12 .2020)$

5. Юрлова Н.С., Скачок И.В. Управление рисками // Вестник НГИЭИ. 2014. № 3 (34). URL: https://cyberleninka. ru/article/n/upravlenie-riskami (дата обращения: 14.12.2020). 